\title{
Research on China's Exchange Online Financial Market: An Exchange Online Financial Capital Asset Pricing Model
}

\author{
Chengyu Yang \\ Institute of European Studies, Chinese Academy of Social Sciences, Beijing, China \\ Email: yangchy@cass.org.cn
}

How to cite this paper: Yang, C.Y. (2019) Research on China's Exchange Online Financial Market: An Exchange Online Financial Capital Asset Pricing Model. American Journal of Industrial and Business Management, 9, 1045-1058.

https://doi.org/10.4236/ajibm.2019.94072

Received: April 3, 2019

Accepted: April 25, 2019

Published: April 28, 2019

Copyright $\odot 2019$ by author(s) and Scientific Research Publishing Inc. This work is licensed under the Creative Commons Attribution International License (CC BY 4.0). http://creativecommons.org/licenses/by/4.0/

\begin{abstract}
China, the world's second largest economy, has become the latest battlefield "fordotcom" companies with online financial exchange businesses booming. While, the traditional CAPM can't price the online financial capital asset successfully, there is no theory of pricing online capital asset. In this paper we build an exchange online financial capital asset pricing model, which improves the performance of the CAPM in application. In our empirical results, the model ECAPM is more successful in pricing online financial capital asset rather than CAPM. Overall, our findings show some arguments of failure of online financial market in US, but of boom in China.
\end{abstract}

\section{Keywords}

China, Exchange Online Financial, Yu'E Bao, Asset Pricing, CAPM

\section{Introduction}

China, the world's second largest economy, has become the latest battlefield "fordotcom" companies with online financial exchange businesses booming. In this paper we call the online financial businesses as exchange online financing, as it describes more accurately to its nature both in financial exchange performances and in online finance instead of internet finance or financing online, etc. The rapid growth of Chinese exchange online financing has been on a roll ever since Alipay, an affiliate of Alibaba Group, rolled out its Yu'E Bao, the country's first ever wealth management product, on June 14, 2013. The potential of this market has not gone unnoticed by other Internet superstars like Tencent and Baidu. Both are now pushing similar online financial products.

The online financial exchange system is taking away the market share of tradi- 
tional banks, and challenging how traditional banks carry out their businesses in China. The exchange online financial business also takes new booming in other countries, like Peer to Pear lending and crowdfunding in US. How to analyze the benefit rate of exchange online financing industry is key and essential for financial supervisors, investors and researchers at present.

There is a large literature argues the return of asset (Beta, $\beta$ ) or asset pricing model which Sharpe, William F. Sharpe (1964) introduces as the theory of market equilibrium under conditions of risk [1], building on the earlier work of Harry Markowitz (1952) on diversification and modern portfolio theory [2]. In finance, the capital asset pricing model (CAPM) is used to determine a theoretically appropriate required rate of return of an asset, if that asset is to be added to an already well diversified portfolio, given that asset is non-diversifiable risk. The model takes into account the asset's sensitivity to non-diversifiable risk (also known as systematic risk or market risk), often represented by the quantity Beta $(\beta)$ in the financial industry, as well as the expected return of the market and a theoretical risk free asset. CAPM suggests that an investor's cost of equity capital is determined by Beta. Robert C. Merton (1973) introduces an inter-temporal capital asset pricing model (ICAPM) that is a consumption-based asset pricing model, and it goes a step further than CAPM in taking into account how investors participate in the market [3]. Most investors do not participate in financial markets for one year, but instead for multiple years. Over longer time periods, investment opportunities might shift as expectations of risk change, resulting in situations in which investors may wish to hedge. For example, an investment may perform better in bear markets, and an investor may consider holding that asset if a downturn in the business cycle is expected. ICAPM uses mean-variance analysis to create normal distribution of consumption risk over time. Because ICAPM covers multiple time periods, multiple beta coefficients are used to determine how many security concerns co-vary with a basket of risky securities. Lucas R. (1978) introduces a consumption-based capital asset pricing model (CCAPM) is used in finance and economics as an expansion of CAPM [4]. The CCAPM factors in consumption as a means of understanding and calculating an expected return on investment. The CCAPM implies that the expected risk premium on a risky asset, defined as the expected return on a risky asset less the risk free return, is proportional to the covariance of its return and consumption in the period of the return. Hersh Shefrin and Meir Statman (1994) derives a behavioral asset pricing theory (BAPM) that develops a capital asset pricing theory in a market where noise traders interact with information traders [5]. Noise traders are traders who commit cognitive errors while information traders are free of cognitive errors. The theory includes the determination of the mean-variance efficient frontier, the return on the market portfolio, the term structure, and option prices. It derives a necessary and sufficient condition for the existence of price efficiency in the presence of noise traders and analyzes the effects of noise traders on price efficiency, volatility, return anomalies, volume, and noise trader survival. Jagannathan and Wang (1996) derives human capital 
CAPM (HCAPM) [6], Campbel Sean D. and Korniotis George M. (2008) implement the HCAPM using the income growth of high income households, rather than aggregate income growth, to proxy the return to human capital (HCRT) [7]. We find that identifying the HCRT with the income growth of affluent households, those who are most likely to hold stocks, substantially improves the performance of the HCAPM. Specifically, the pricing errors, $\mathrm{R}$ square's, average returns on factor mimicking portfolios, and performance relative to other macro-finance models uniformly improve as the HCRT is identified with the income growth of successively more affluent households. Liang Zou (2006) derives a best-beta CAPM (BCAPM) that maintains the CAPM's theoretical appeal and analytical simplicity yet unambiguously improves its pricing accuracy. Empirical observations suggest that the BCAPM predicts expected returns better than the CAPM by $20 \%$ to $30 \%$ annually [8].

While the previous literatures have also analyzed the exchange online financial business, Christiansen H. (2001) defines an electronic financial transaction is a financial transaction that depends on the Internet or a similar network to which households or non-financial enterprises have access [9]. Allen et al. (2002) proposes that e-finance is the provision of financial services and markets using electronic communication and computer [10]. Nikil Chande (2008) provides an overview of the different kinds of non-bank retail payments schemes currently available, include electronic bill consolidators, such as epost; online payment providers, like PayPal; and pre-funded schemes, such as retailers' gift cards. The author also discusses the main risks associated with each of the schemes, such as bankruptcy, banker, security, market, and liquidity risks [11]. Ian Galloway (2009) analyses peer-to-peer lending and community development finance. Popular P2P platforms include eBay and Craigslist, for example, which have transformed the market for used consumer goods in recent years. Increasingly popular, however, are P2P lending sites that facilitate debt transactions by directly connecting borrowers and lenders on the Internet [12]. Hernández-Murillo R, Llobet G, Fuentes R. (2010) analyses the strategic online banking adoption [13]. Wojciech Hardy et al. (2013) proposes a theoretical framework to capture the underlying mechanisms of the innovative online crowd-funding [14].

In this paper we develop a methodology to value expected returns of the market or beta in the condition of online financial exchange industry including online money market funds, which is developed by traditional CAPM. Here we call it as Exchange online Financial Capital Asset Pricing Model (ECAPM). The expected return of the market (Beta) is determined by exchange online financial betas, measures of risk with respect to the mean-variance-efficient portfolio in this model. This portfolio differs from the Markowitz market portfolio as it largely depends on the preferences of the saving rate and interbank offered rate, and sometimes deposit rate also takes function. The model premise is market interaction between information traders and exchange online financial traders.

The problem with the traditional approach is that CAPM has its empirical flaw and the existence of more modern approaches to asset pricing and portfolio 
selection. Another ICAPM is that it assumes that consumer expectations are homogenous, meaning that it cannot take into account individual risk preferences. Also it likes others such as, BAPM, BCAPM, CCAPM and HCAPM have discussed the pricing performances without considering online financial exchange business including money market funds.

We propose one method to derive and certify the beta by comparing different development of online financial exchange industry between China and USA. Some relative literatures are: Jiaqin Yang, Li Cheng and Xia Luo (2009) describes a comparative study about the issues in the current e-banking services among the young consumers between China and USA. They explore that different cultures and traditions will play a role in the development of e-banking industry among different nations [15].

To give an example of our findings using this approach: exchange online investment service, which is offered by Alipay, China's leading online payment provider, and "Tian Hong" Asset Management, have attracted investment deposits of more than $\$ 65.96$ billion by Feb 14, 2013. How to analyze the nature of benefit on investment deposits online is very helpful for us to verify the availability of ECAPM. The operation process of "Yu'E Bao" is shown in Figure 1. Savings accounts offer a minuscule interest rate of $0.35 \%$ a year while a one year fixed deposit can pay 3.3\%. Yu'E Bao and other similar products provided by tech companies are offering about $4.25 \%$ a year (while all exchange online financing products mentioned above are declining, narrowing their advantages over wealth management products offered by banks). And online money market funds have forced banks to offer similar products, but banks are lobbying regulators to clamp down on the money market funds before they siphon off more of their deposits. These funds invest in the interbank market and domestic bonds. China maintains a ceiling on interest rates paid on deposits at the nation's banks but it has vowed to make interest rates more market-based. As we known online money market funds, which aren't subject to the limits, have been able to offer

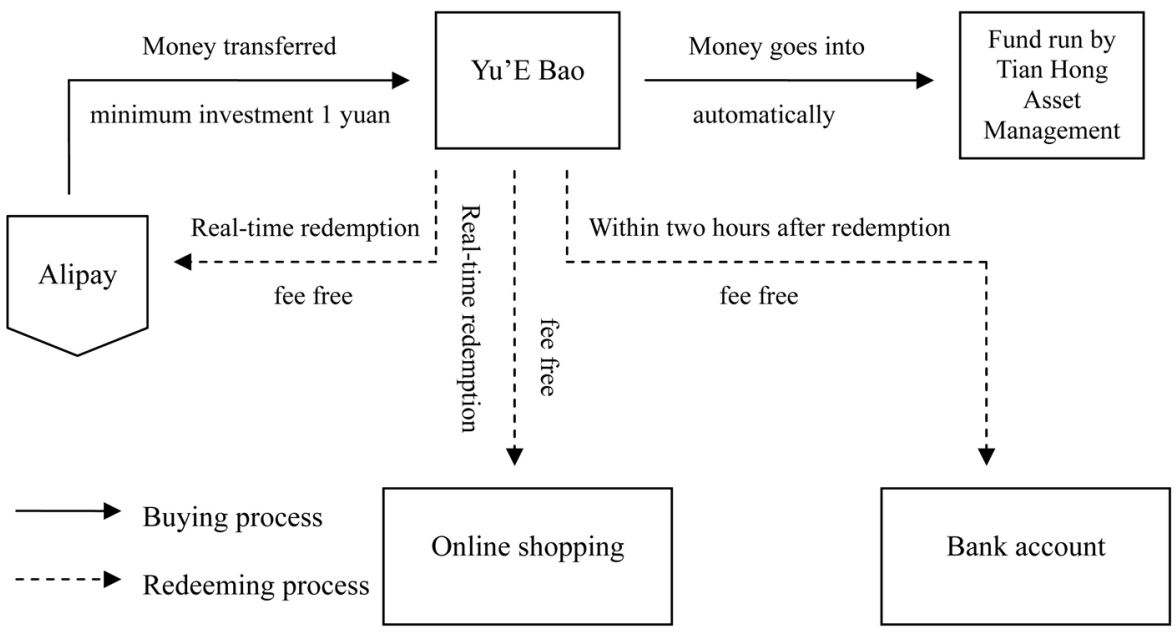

Figure 1. How Yu’E Bao works. 
substantially higher returns, effectively helping regulators in their deregulation efforts, though raising concerns at the nation's banks.

The results provide direct evidence for Yu'E Bao allows customers to invest any balance on their account in a money market fund. On the other hand, it still has some potential risks. For example, the first comes from declining yields. Yields on all exchange online financing products mentioned above are declining, narrowing their advantages over wealth management products offered by banks. Secondly, tighten regulations. China's securities regulator would work with other agencies to issue a set of rules to govern the burgeoning Exchange online Financing industry. Despite being "generally supportive" of exchange online financing, the China Securities Regulatory Commission thought the nascent sector still needs proper regulation and guidance. The final is capital safety. As Exchange online financing relies on the Web, online personal information and safety will always be a concern. Adding to this worry is the fact that people's online accounts can be hacked via malicious viruses and their money stolen.

We believe that the main contribution of our paper is methodological analysis on expected return of market (Beta) in the exchange online financial industry. The ECAPM is an innovative model developed by traditional CAPM, ECAPM is efficient and effective due to its simplicity and utility in a situation of online money market funds.

Our results suggest that we can use ECAPM model to derive or predict the expected return of the market in exchange online financial industry including online money market funds. Online money market funds put pressure on the central bank's ceiling on bank deposit rates, Central Bank governor should refine regulations covering online funds but do not necessary to have intention of cracking down on these competitors to the nation's banks.

\section{The General Approach}

While the precise implementation details differ, the basic empirical strategy to incorporate exchange online financial industry into the CAPM, or ECAPM, is straightforward. Consider the return to interbank offered market, $R_{t}^{F}$, and the return to exchange online money market fund market, $R_{t}^{E F}$. Also, let the time-invariant, aggregate share of exchange online financial wealth in total return be denoted as $\omega$. The return on the exchange online financial market portfolio, where we note $R_{t}^{M}$ at the time $t$, is simply a weighted average of the return to interbank offered and exchange online money market fund market, $R_{t}^{M}=\omega R_{t}^{E F}+(1-\omega) R_{t}^{F}$.

The proxy for the return to exchange online money market funds market is the return on a broad online money market funds portfolio. But, for exchange online financial industry, the return to interbank offered market is far more difficult to observe. As a result, an assumption must be made about how to measure $R_{t}^{F}$.

We assume that the expected return to interbank offered market is constant. 
Under this assumption, the realized return is a linear function of the current interbank offered rate, $b_{t}$. Finally, if one takes a stand on the fraction of return to interbank offered market in total return, $1-\omega$, the return to the exchange online financial market portfolio, $R_{t}^{M}$, may be constructed and asset betas may be calculated. Alternatively, one can simply use both $R_{t}^{E F}$ and $R_{t}^{F}$ in a two factor expected return beta model. Using this approach the return on a particular exchange online financial asset $i, R_{i t}$, can be expressed as a linear function of the exchange online financial industry's "exchange online money market fund market" beta and "interbank offered market" beta as follows:

$$
\begin{aligned}
R_{i t}-R_{f t} & =\left(R_{i t}^{F}-R_{f t}\right)+\left(R_{i t}^{E F}-R_{f t}\right) \\
& =\beta_{i}^{F}\left(R_{t}^{F}-R_{f t}\right)+\beta_{i}^{E F}\left(R_{t}^{E F}-R_{f t}\right)+\varepsilon_{i t}
\end{aligned}
$$

Now take account on the return to interbank offered market, which is the $R_{i t}^{F}$ in the form (1). Assume that an individual only views the outcome of any investment of interbank offered market that considers the preference in terms of the wealth which changes in the market. Also assume that measuring the return to traditional financial wealth with the simple interbank offered rate, does not hinge on the methodology used to measure the return to traditional financial wealth. In assessing the desirability of a particular investment, however, he is willing to act on the basis of only one parameter, his wealth marginal $W_{t}^{i}$ in interbank offered market $i$ at the time $t$. This can be represented by a total utility function of the form:

$$
U=f\left(W_{t}\right)
$$

where $W_{t}$ indicates wealth to interbank offered market at the time $t$.

The Euler equation is

$$
U^{\prime}\left(W_{t}\right)=E\left\{U^{\prime}\left(W_{t+1}\right) * \frac{1+R_{i t+1}^{F}}{1+\rho}\right\}
$$

where $R_{i t+1}^{F}$, is the rate of return to interbank offered market (interbank rate) for any exchange online financial industry's asset $i$ at the time $t+1$.

We will derive an asset pricing equation resembling the CAPM from starting from the Euler Equation subject to some assumptions. The first assumption is that $U\left(W_{t}\right)=\ln \left(W_{t}\right)$ which implies that $U^{\prime}\left(W_{t}\right)=1 / W_{t}$. From (3) we then get

$$
\frac{1}{W_{t}}=E\left\{\frac{1}{W_{t+1}} * \frac{1+R_{i t+1}^{F}}{1+\rho}\right\} \Leftrightarrow E\left\{\frac{W_{t}}{W_{t+1}} * \frac{1+R_{i t+1}^{F}}{1+\rho}\right\}=1
$$

Equation (4) holds for any asset, so in particular it holds for the safe asset giving,

$$
E\left\{\frac{W_{t}}{W_{t+1}} * \frac{1+R_{f t}}{1+\rho}\right\}=1
$$

Now subtract (5) from (4) and we get,

$$
E R_{i t+1}^{F}-R_{f t}=E\left\{\frac{W_{t+1}-W_{t}}{W_{t}}\left(R_{i t+1}^{F}-R_{f t}\right)\right\}
$$


Since $\frac{W_{t+1}-W_{t}}{W_{t}}$ is the usual measure of the growth rate in investor's wealth, we prefer the form (6). Now we assume that the exchange online financial asset such that the return $R_{t+1}^{F}$ is equal to interbank offered rate. Equation (6) will then have form

$$
E R_{i t}^{F}-R_{f t}=E\left\{R_{t}^{F}\left(R_{i t}^{F}-R_{f t}\right)\right\}
$$

which can be transformed to

$$
E R_{i t}^{F}-R_{f t}=\frac{1}{1-E R_{t}^{F}} \operatorname{Cov}\left(R_{t}^{F}, R_{i t}^{F}-R_{f t}\right)
$$

Since (8) has to hold for any asset it also has to hold for $i^{*}$. We then get

$$
E R_{t}^{F}-R_{f t}=\frac{1}{1-E R_{t}^{F}} \operatorname{Var}\left(R_{t}^{F}\right)
$$

Divide Equation (8) by Equation (9) and we get

$$
\frac{E R_{i t}^{F}-R_{f t}}{E R_{t}^{F}-R_{f t}}=\frac{\operatorname{Cov}\left(R_{t}^{F}, R_{i}^{F}-R_{f t}\right)}{\operatorname{Var}\left(R_{t}^{F}\right)}
$$

If we denote the coefficient from a regression of $R_{i}^{F}$ on the interbank offered rate by $\beta_{i}^{F}$ we get

$$
R_{i t}^{F}-R_{f t}=\beta_{i}^{F} *\left(R_{t}^{F}-R_{f t}\right)+\mu_{i t}
$$

Form (11) generally identifies the structure of CAPM model, $R_{i t}^{F}$ is the rate of return to interbank offered market for any exchange online financial industry's asset $i$ at the time $t . R_{f t}$ is the pure (riskless) interest rate at the time $t$, $R_{t}^{F}$ is the interbank offered rate at the time $t, \beta_{i}^{F}$ is the risk measure of interbank offered system, $\mu_{i t}$ is the random error.

Implementing the dynamic ECAPM, however, is complicated by the fact that an explicit forecasting model needs to specified and estimated. In this case, the revisions to future interbank offered rates depend on the information set used to predict the future levels of return, which implies that the inference of asset pricing tests can hinge on the state variables included in this information set. Therefore, in this paper we focus on the static ECAPM. This paper reveals that the main conclusions drawn from measuring the return to traditional financial wealth with the simple rate of interbank offered, does not hinge on the methodology used to measure the return to traditional financial wealth.

Then move to focus on the return to exchange online money market fund market, as the $R_{i t}^{E F}$ in the form (1). On exchange online financial market, we have an assumption that the return to exchange online financial asset depend on the return to exchange online money market fund market $i$ and return to the online money market fund market portfolio $E M$. For any exchange online money market fund $i$, we have the expression CAPM,

$$
R_{i t}^{E F}-R_{f t}=\beta_{i}^{E F} *\left(R_{t}^{E F}-R_{f t}\right)+\eta_{i t}
$$


where $R_{i t}^{E F}$, is the rate of return to online money market fund market for any exchange online financial industry's asset $i$ at the time $t, R_{t}^{E F}$ is the rate return to the online money market fund market portfolio.

In conclusion, form (13) expresses the portfolio return rate of any exchange online financial asset $i$ at the time $t$,

$$
R_{i t}-R_{f t}=\alpha_{i t}+\beta_{i}^{F} *\left(R_{t}^{F}-R_{f t}\right)+\beta_{i}^{E F} *\left(R_{t}^{E F}-R_{f t}\right)+\varepsilon_{i t}
$$

At the time $t$, the return on a particular exchange online financial industry's asset $i, R_{i t}$, can be expressed as a linear function of the exchange online financial industry's "exchange Online Money market Fund Market" beta, $\beta_{i}^{E F}$ and "interbank offered market" beta, $\beta_{i}^{F}$, where $R_{t}^{F}$ is the rate of return to interbank offered market, which use the interbank offered rate in this paper. $R_{t}^{E F}$ is the rate of return to online money market fund market portfolio. $R_{f t}$ is the pure (Riskless) interest rate.

\section{Data Description}

\subsection{Rate of Return to Online Money Market Fund Market Portfolio}

The monthly rate of return to online money market fund market portfolio from respective 25 money market funds in China during the period from June 2013 through June 2014 were analyzed in the manner suggested by the theory.

Here choose the data that is the 25 money market funds which represents those top biggest scales on the Chinese money market funds market, and their average assets are more than about 150,000,000\$. Take the $F_{i}$ as the scale of money market fund $i$ on April 30, 2014; the weight of the rate to total scale of money market funds, that is $\theta_{i}$, we get

$$
\theta_{i}=\frac{F_{i}}{\sum F_{j}}, \text { for } j=1, \cdots, 25
$$

For any month $t$, the monthly rate of return money market fund market portfolio equal to the weights of 25 money market funds multiplied by the sum of the monthly rate of return (i.e. $R_{i t}$ ), then have the expression of the monthly rate of return money market fund market portfolio $R_{t}^{E F}$,

$$
R_{t}^{E F}=\sum_{i} \theta_{i} R_{i t}, \text { for } i=1, \cdots, 25
$$

\subsection{Rate of Return to Interbank Offered Market}

Express the interbank offered rate as the return to interbank offered market. The interbank offered rates data are from Shanghai Interbank Offered Rate during the period from June 2013 through June 2014. The average interbank offered rate for a day, a week, a month and a quarter respectively at any month $t$, noted them as $b_{t}^{D}, b_{t}^{W}, b_{t}^{M}, b_{t}^{Q}$.

In panel A of Table 1 we report summary statistics for all four interbank offered rate series as well as the rate of return online money market fund market portfolio, the factors in the ECAPM. The average interbank offered rates are 
Table 1. Descriptive statistics.

\begin{tabular}{cccccc}
\hline & $b_{t}^{D}$ & $b_{t}^{W}$ & $b_{t}^{M}$ & $b_{t}^{Q}$ & MKRT \\
\hline Descriptive Statistics: Mean & 3.37 & 4.21 & 5.26 & 5.08 & 4.65 \\
Descriptive Statistics: Standard Deviation & 1.12 & 0.98 & 0.91 & 0.38 & 0.51 \\
Descriptive Statistics: Autocorrelation Coef. & 0.22 & 0.25 & 0.41 & 0.75 & 0.61 \\
Correlation Matrix: $b_{t}^{D}$ & 1 & & & & \\
Correlation Matrix: $b_{t}^{W}$ & 0.94 & 1 & & & \\
Correlation Matrix: $b_{t}^{M}$ & 0.81 & 0.90 & 1 & & \\
Correlation Matrix: $\quad b_{t}^{Q}$ & -0.21 & 0.01 & 0.04 & 1 & \\
Correlation Matrix: MKRT & -0.18 & 0.11 & 0.34 & 0.66 & 1 \\
\hline
\end{tabular}

This table includes descriptive statistics for various interbank offered rates and for the rate of return to online money market fund market portfolio. $b_{t}^{D}$ is the average interbank offered rate for a day. $b_{t}^{W}, b_{t}^{M}$ and $b_{t}^{o}$ represent the average interbank offered rate for a week, a month and a quarter, respectively. The interbank offered rates data are from Shanghai Interbank Offered Rate. The rate of return to online money market fund market portfolio (MKRT) is the value-weighted return of 25 tops money market funds listed on the Hexun database. The time period is from June 2013 to June 2014.

higher than risk free rate (one year fixed saving rate, $R_{f}$ ). Chinese banks were short of cash, the interbank borrowing cost jumped, as huge expansion of Chinese online financial market at that period from June 2013 to June 2014.

Table 1 reports the correlation matrix between the four interbank offered rates and the rate of return to online money market fund market portfolio. The correlation between interbank offered rate for a day and interbank offered rate for a week is mostly correlated. Specifically, the correlation between $b_{t}^{D}$ and $b_{t}^{W}$ is $94 \%$, while the correlation between $b_{t}^{D}$ and $b_{t}^{M}$ is $81 \%$. This discrepancy among interbank offered rates as while as the rates of return to interbank offered market is further illustrated by the pattern in correlation between the return to interbank offered market and the exchange online money market fund market return. At the aggregate level, the return to interbank offered market is positively correlated with the exchange online money market fund market return. The correlation between the return to exchange online money market fund market and the return to interbank offered market for a quarter, however, is positive and rises as the degree of affluence rises.

\section{Main Empirical Results}

In this section we present our main empirical results. First, we present results of a traditional estimate of the CAPM. We then discuss the level and significance of the risk premiums on the various measures of the excess return to interbank offered market, which are $b_{t}^{D}, b_{t}^{W}, b_{t}^{M}, b_{t}^{Q}$, and the excess return to online money market fund market portfolio related to the four proxies of the return to interbank offered market. Finally, we compare the CAPM and ECAPM model.

Table 2 presents results from the estimated ECAPM model. We estimate the model described by Equation (13). Use four different proxies for the interbank 
Table 2. Fama and MacBeth risk premiums in the CAPM and ECAPM.

\begin{tabular}{ccccccc}
\hline & Intercept & NBR & SHIBOR & MKRT & $R^{2}$ & Adj $R^{2}$ \\
\hline CAPM & 1.491 & 0.18 & & & 0.16 & 0.09 \\
CAPM: FMB $t$-statistic & 17.76 & 1.41 & & & & \\
ECAPM_D & 0.005 & & -0.13 & 1.00 & 0.71 & 0.68 \\
ECAPM_D: FMB $t$-statistic & 0.06 & & -6.04 & 21.41 & & \\
ECAPM_W & -0.001 & & -0.14 & 1.07 & 0.71 & 0.68 \\
ECAPM_W: FMB $t$-statistic & -0.02 & & -5.70 & 23.33 & & \\
ECAPM_M & 0.05 & & -0.13 & 1.13 & 0.70 & 0.67 \\
ECAPM_M: FMB $t$-statistic & 0.58 & & -4.89 & 23.09 & & \\
ECAPM_Q & -0.278 & & 0.11 & 1.00 & 0.68 & 0.65 \\
ECAPM1_Q FMB $t$-statistic & -2.03 & & 1.31 & 15.70 & & \\
\hline
\end{tabular}

The table includes the Fama and MacBeth (FMB) (1973) risk premiums estimated from the four CAPM and four ECAPM specifications [16]. For the CAPM the traditional financial market return (i.e. in this paper we use the rate of return to national debt in China, NBR) is the only risk factor. For the ECAPM the risk factors are the return to interbank offered market (i.e. SHIBOR) and the return to exchange online money market fund market (i.e. we use the rate of return to online money market fund market portfolio in China, MKRT). We examine four proxies for the return to interbank offered market: the interbank offered rate for a day, $b^{D}$, the interbank offered rate for a week, $b^{w}$, the interbank offered rate for a month, $b^{w}$, the interbank offered rate for a quarter, $b^{Q}$. The interbank offered rates data are from Shanghai Interbank Offered Rate. The FMB t-statistics are reported beneath the risk premiums. The time period is from June 2013 to June 2014. The test assets are the 25 top money market funds listed on the Hexun Database. In this study, we cited data from a professional Chinese financial website named HEXUN, which evaluated online money market performance every year from 2010 on all Chinese exchange online financial firms.

offered rate, the interbank offered rate for a day, a week, a month and a quarter $b^{D}, b^{W}, b^{M}, b^{Q}$ respectively, and refer to the estimated exchange online financial models as ECAPM_D, ECAPM_W, ECAPM_M and ECAPM_Q. A traditional estimate of the CAPM that excludes any measure of exchange online financial industry is presented in the top row of Table 2 for comparison, we note it as CAPM. Aside from the parameter estimates, we present Fama and MacBeth (1973) t-statistics that account for measurement error in the first-pass beta estimates [16]. Also present both the unadjusted and adjusted $R^{2}$ of the second-pass regression as a measure of model fit.

Looking at the estimates under the excess return to national debt (NBR) column of Table 2 reveals that the effect of return to national debt market affluent expected return of exchange online financial asset, the coefficient is 0.18 in the case of CAPM model. However, the power of effect is weak when use the traditional CAPM to calculate the expected return of exchange online financial asset.

Now, focus on the estimates under the excess return to exchange online financial market, where are the interbank offered market and exchange online money market fund market. Looking at the estimates under the return to interbank offered market (SHIBOR) column of Table 2 reveals that the effect of interbank offered market on expected returns is estimated to be significant correlation with expected return of online financial asset. The estimated coefficient is negative in 
the case of the ECAPM_D, ECAPM_W and ECAPM_M, positive in the case of the ECAPM_Q. In particular, notes that the effect of the interbank offered market for a quarter Beta on its expected return is estimated to be positive in the ECAPM_Q. In all other cases, the market beta associated with each interbank offered market is estimated to be negative. But the values absolute of all Beta associated with all interbank offered markets are from 0.11 to 0.14 , which reveals that online financial assets are much less influenced by interbank offered market.

The extent to which identifying the interbank offered market depends on the measure of statistical significance. In the case of the Fama-MacBeth $t$-statistics, the pattern is clear. The return to interbank offered market associated with successively more affluent return to exchange online financial asset has a more statistically significant effect on expected return. The $t$-statistic on the interbank offered market rises monotonically from -6.04 in the case of the ECAPM_D to 1.31 in the case of the ECAPM_Q.

Next, facing at the estimates under the return to exchange online money market fund market (MKRT) column of Table 2 reveals that the effect of exchange online money market fund market on expected returns is estimated to significantly correlate to the expected return of online financial assets. The estimated coefficient is positive in all cases, and strictly not less than 1.00 , which reveals that the effect of exchange online money market fund market on exchange online financial asset's expect return is more important than the effect of interbank offered market for a day (1.00 vs -0.13$)$, a week (1.07 vs -0.14$)$, a month (1.13 vs -0.13$)$ and a quarter (1.00 vs 0.11$)$.

Finally, compare the CAPM and ECAPM model. The traditional CAPM measures that results as measured by adjusted $R^{2}$ is ambiguous. The adjusted $R^{2}$ of the CAPM that ignores all exchange online financial market is $9 \%$ indicating that the simple CAPM explains a modest proportion of the variation in expected returns on exchange online financial asset. However, the EAPM measure that results in the largest improvement in model fit, as measured by adjusted $R^{2}$ is unambiguous. The improvement of fit is from adding the exchange online financial markets, which are the interbank offered market and the exchange online money market fund market. Looking at the fit measures in Table 2 reveals that the adjusted $R^{2}$ improves steadily from $65 \%$ to $68 \%$ as the measure of the return to interbank offered market and the return to exchange online money market fund market is restricted from the ECAPM_Q to the ECAPM_D. The improvement in fit from adding these alternative measures of the return to exchange online financial markets indicates both that exchange online financial market's risks are the important determinants of expected returns. A measure of the return to exchange online financial asset whit ECAPM, which is more closely aligned with the characteristics of exchange online financial industry, improves the performance of the ECAPM substantially over a measure with the traditional CAPM.

Overall, the main results in Table 2 indicate that the traditional CAPM can't price the online financial capital asset successfully, while the ECAPM improves 
the performance with using the exchange online financial markets, there are the interbank offered market and the online money market fund market. We also find that the return of exchange online financial capital asset is significant correlated with different types of rate interbank offered, it is more correlated with online money market fund market than interbank offered market. We build the ECAPM that improves the CAPM in application of pricing exchange online financial capital asset.

\section{Conclusions}

The version of the CAPM developed by Sharpe (1964) and Lintner (1965) has never been an empirical success in application to exchange online financial asset [17] [18]. The problems are serious enough to invalidate most applications of the CAPM. In this paper, we take a fresh look at the ECAPM motivated by improving the traditional CAPM to calculate the expected return to exchange online financial asset. ECAPM is more closely aligned with the characteristics of exchange online financial industry, improves the performance of the ECAPM substantially over a measure with the traditional CAPM.

We measure the return to exchange online money market fund market using the return rate data from 25 top money market funds listed on the Hexun database in China. This data set provides a long time series on the return rates of the top exchange online money market fund in China because of rapid increase on Chinese money funds over June 2013 to June 2014 period. Unfortunately, such data cannot cover other countries' online financial market, as US data is much difficult to obtain that its online financial market started much early but Paypal loses. But in China the saving ratio is constantly higher than the rest of world, when the Chinese online financial industry boom, for example Alipay, the rise is surprising high.

Our empirical analysis demonstrates that version of the ECAPM (ECAPM_D, ECAPM_W, ECAPM_M, ECAPM_Q) that identifies the return to interbank offered market with the interbank offered rate are successful in many dimensions. These versions of the ECAPM explain the returns on the interbank offered rate for one day, one week and one month more successfully than the ECAPM implemented with interbank offered rate for one quarter (ECAPM_Q). Moreover, the degree of fit is more improved in the model of ECAPM_D and ECAPM_W, which implementing the interbank offered rate for one day and one week, respectively.

We also find that the empirical performance of the ECAPM, implemented with the risks of interbank offered market and of exchange online money market fund market, is more compatible to apply than capital asset pricing model in part of exchange online capital asset. This finding is interesting because it suggests that exchange online financial capital asset pricing model is more successful in application.

It shows that some arguments of failure of online financial market in US, for 
example, the Paypal. The results of Table 2 reveals that, the alpha of online financial capital asset is much lower than that of the traditional financial capital asset which is calculated by CAPM, additionally interbank offered market has negative correlation with it, the most excess return to online financial capital asset comes from exchange online money market fund market portfolio. But very low saving ratio in US can't make exchange online money market fund market be enough scale as that in China. At the same time interbank offered rate has weakly opposite effect on expected return, so if the interbank offered rate remains relative high level at that time, then the exchange online financial business will fail, such as Paypal, as the interbank offered rate was relative quite high in financial crisis because of low liquidity.

These results consistently show that the exchange online risks of affluent the return to exchange online financial asset is the priced risk factors that successfully explain variation in expected return of exchange online financial asset. Moreover, implementing the ECAPM by identifying the return to exchange online financial asset with the interbank offered market and the exchange online money market fund market is more successful than an implementation employing a simple CAPM. We find that examining the ECAPM improves our understanding of the empirical link between risk and return in the exchange online financial market.

\section{Conflicts of Interest}

The author declares no conflicts of interest regarding the publication of this paper.

\section{References}

[1] Sharpe, W. (1964) Capital Asset Prices: A Theory of Market Equilibrium under Conditions of Risk. The Journal of Finance, 19, 425-442. https://doi.org/10.1111/j.1540-6261.1964.tb02865.x

[2] Markowitz, H. (1952) Portfolio Selection. The Journal of Finance, 7, 77-91. https://doi.org/10.2307/2975974

[3] Merton, R. (1973) An Intertemporal Capital Asset Pricing Model. Econometrica, 41, 867-887. https://doi.org/10.2307/1913811

[4] Lucas, R. (1978) Asset Prices in an Exchange Economy. Econometrica, 46, 1429-1445. https://doi.org/10.2307/1913837

[5] Shefrin, H. and Statman, M. (1994). Behavioral Capital Asset Pricing Theory. The Journal of Financial and Quantitative Analysis, 29, 323-349. https://doi.org/10.2307/2331334

[6] Jagannathan, R. and Wang, Z. (1996) The Conditional CAPM and the Cross-Section of Expected Returns. The Journal of Finance, 51, 3-53. https://doi.org/10.2307/2329301

[7] Campbell, S.D. and Korniotis, G.M. (2008) The Human Capital That Matters: Expected Returns and the Income of Affluent Households, No 2008-09, Finance and Economics Discussion Series, Board of Governors of the Federal Reserve System (US). 
[8] Zhou, L. (2006) The Best-Beta CAPM. Applied Financial Economics Letters, 7, 131-137. https://doi.org/10.1080/13504850500395993

[9] Christiansen, H. (2001) Electronic Finance: Economics and Institutional Factors. OECD Financial Affair Division Occasional Paper, 2.

[10] Allen, F., McAndrews, J. and Strahan, P. (2002) E-Finance: An Introduction. Journal of Financial Services Research, 22, 5-27. https://doi.org/10.1023/A:1016007126394

[11] Chande, N. (2008) A Survey and Risk Analysis of Selected Non-Bank Retail Payments Systems. Bank of Canada Discussion Paper, 17.

[12] Galloway, I. (2009) Peer-to-Peer Lending and Community Development Finance, No 2009-06. Community Development Investment Center Working Paper, Federal Reserve Bank of San Francisco, San Francisco.

[13] Hernandez-Murillo, R., Llobet, G. and Fuentes, R. (2010) Strategic Online-Banking Adoption. FRB of St. Louis Working Paper, No. 2006-058B. https://doi.org/10.2139/ssrn.941478

[14] Hardy, W., Krawczyk, M. and Tyrowicz, J. (2013) Why Is Online Piracy Ethically Different from Theft? A Vignette Experiment. Working Papers Faculty of Economic Sciences, University of Warsaw, No. 2013-24.

[15] Yang, J., Cheng, L. and Luo, X. (2009) A Comparative Study on e-Banking Services between China and USA. Journal International Journal of Electronic Finance, 3, 235-252. https://doi.org/10.1504/IJEF.2009.027848

[16] Fama, E.F. and MacBeth, J.D. (1973) Risk, Return and Equilibrium: Empirical Test. Journal of Political Economy, 71, 607-639. https://doi.org/10.1086/260061

[17] Sharpe, W.F. (1964) Capital Asset Prices: A Theory of Market Equilibrium under Conditions of Risk. Journal of Finance, 19, 425-442.

https://doi.org/10.1111/j.1540-6261.1964.tb02865.x

[18] Lintner, J. (1965) The Valuation of Risk Assets and the Selection of Risky Investments in Stock Portfolios and Capital Budgets. The Review of Economics and Statistics, 47, 13-37. https://doi.org/10.2307/1924119 